\title{
BMJ Open Assessing the association of oxytocin augmentation with obstetric anal sphincter injury in nulliparous women: a population-based, case-control study
}

\author{
Astrid B Rygh,, ${ }^{1,2}$ Finn Egil Skjeldestad, ${ }^{3}$ Hartwig Körner, ${ }^{2,4}$ Torbjørn M Eggebø ${ }^{1,5}$
}

To cite: Rygh $A B$, Skjeldestad FE, Körner $\mathrm{H}$, et al. Assessing the association of oxytocin augmentation with obstetric anal sphincter injury in nulliparous women: a population-based, casecontrol study. BMJ Open 2014;4:e004592.

doi:10.1136/bmjopen-2013004592

- Prepublication history for this paper is available online. To view these files please visit the journal online (http://dx.doi.org/10.1136/ bmjopen-2013-004592).

Received 1 December 2013 Revised 27 June 2014 Accepted 8 July 2014

CrossMark

For numbered affiliations see end of article.

Correspondence to Dr Astrid B Rygh; ast-ry@online.no

\section{ABSTRACT}

Objective: To assess the association of oxytocin augmentation with obstetric anal sphincter injury among nulliparous women.

Design: Population-based, case-control study.

Setting: Primary and secondary teaching hospital serving a Norwegian region.

Population: 15476 nulliparous women with spontaneous start of labour, single cephalic presentation and gestation $\geq 37$ weeks delivering vaginally between 1999 and 2012 .

Methods: Based on the presence or absence of oxytocin augmentation, episiotomy, operative vaginal delivery and birth weight ( $<4000$ vs $\geq 4000 \mathrm{~g})$, we modelled in logistic regression the best fit for prediction of anal sphincter injury. Within the modified model of main exposures, we tested for possible confounding, and interactions between maternal age, ethnicity, occiput posterior position and epidural analgaesia.

Main outcome measure: Obstetric anal sphincter injury.

Results: 0xytocin augmentation was associated with a higher OR of obstetric anal sphincter injuries in women giving spontaneous birth to infants weighing $<4000 \mathrm{~g}$ (OR 1.8; $95 \% \mathrm{Cl} 1.5$ to 2.2). Episiotomy was not associated with sphincter injuries in spontaneous births, but with a lower OR in operative vaginal deliveries. Spontaneous delivery of infants weighing $\geq 4000 \mathrm{~g}$ was associated with a threefold higher OR, and epidural analgaesia was associated with a $30 \%$ lower OR in comparison to no epidural analgaesia.

Conclusions: 0xytocin augmentation was associated with a higher OR of obstetric anal sphincter injuries during spontaneous deliveries of normal-size infants. We observed a considerable effect modification between the most important factors predicting anal sphincter injuries in the active second stage of labour.

\section{INTRODUCTION}

Obstetric anal sphincter injuries occur in $0.5-5.0 \%$ of vaginal deliveries ${ }^{1}$ with a subsequently increased risk of faecal incontinence. $^{2-4}$ Nulliparity, ${ }^{1} 35$ high birth weight

\section{Strengths and limitations of this study}

- Stratifying by the main risk factors that are active during the expulsive phase of labour and testing for confounders are strengths of the study.

- We reveal how oxytocin augmentation interacts with the major factors active in the expulsive phase of labour.

- The study is based on prospectively collected data from a large, unselected population, which makes bias unlikely.

- The study design is a limitation, as we cannot prove causality between oxytocin augmentation and obstetric anal sphincter injuries in an observational study.

$(\mathrm{BW}),{ }^{1} 3{ }^{3} 5{ }^{6}$ operative vaginal delivery, ${ }^{1} 35$ advanced maternal age, ${ }^{156}$ Asian or African ethnicity, ${ }^{1} 7$ and prolonged second stage of labour $^{3} 78$ are consistently reported as risk factors for obstetric anal sphincter injuries, whereas the effect of epidural analgaesia 910 and episiotomy ${ }^{11-13}$ is debated. However, only a few authors have evaluated oxytocin augmentation as a possible risk factor for obstetric anal sphincter injuries. ${ }^{5} 14 \quad 15$ Further, the current literature dealing with risk factors for obstetric anal sphincter injuries has not sufficiently addressed their possible interactions. Studies usually present a summary of associations between risk factors and obstetric anal sphincter injuries adjusted for confounders without investigating effect modification, that is, exploring whether the effects are uniform across various levels of the studied risk factors.

In many delivery units, oxytocin augmentation is used during more than half of births. ${ }^{1617}$ Oxytocin augmentation has been shown to shorten the duration of labour, but not to decrease the need for operative deliveries. $^{18}$ We hypothesise that oxytocin augmentation may reduce control over 
contractions and impair perineal support by causing the delivery to progress too quickly, and thereby increase the risk of perineal injury. Thus, the widespread use of oxytocin in daily obstetric practice calls for an exploration of its possible harmful effects. The aim of our study was to assess the association between oxytocin augmentation and obstetric anal sphincter injuries in a dynamic model related to the active second stage of labour.

\section{MATERIALS AND METHODS}

The Department of Obstetrics and Gynecology of Stavanger University Hospital serves as the only delivery unit for a population of 320000 people, and approximately 4500 deliveries occur there annually. From 1996 onward, all obstetric data have been consecutively recorded. The electronic database consists of clearly defined variables, and is continuously maintained using standardised procedures for data entry and quality control. During the study period, 15 May 1999 to 15 May 2012, 56517 women with a pregnancy duration of $\geq 23$ weeks of gestation delivered infants with a BW of $>300 \mathrm{~g}$ in the department. Estimated day of delivery was determined by second trimester ultrasound scan or from menstrual data when no ultrasound examination was performed. We restricted the study population to nulliparous women whose labour started spontaneously, with single cephalic presentation, pregnancies of $\geq 37$ weeks of gestation (Group 1 in Robson's Ten Group Classification System; TGCS ${ }^{19}$ ) and who delivered vaginally. After excluding 69 women with missing data (52 without an estimated day of delivery, 17 with missing information of fetal presentation at delivery), this casecontrol study comprised 15476 women.

The main outcome measure was obstetric anal sphincter injuries as defined by the International Continence Society, that is, partial or complete tears of the anal sphincter muscles, with or without disruption of the anal mucosa (grades 3-4 perineal tears). ${ }^{20}$ When an obstetric anal sphincter injury was suspected, the obstetrician on call diagnosed the grade of the tear during surgical repair.

Oxytocin augmentation was defined as oxytocin used to stimulate contractions during established labour. An intravenous infusion of 5 international units $(0.01 \mathrm{mg})$ of oxytocin in $500 \mathrm{~mL}$ saline was administered, starting with $30 \mathrm{~mL} / \mathrm{h}$ and a dose increment of $15 \mathrm{~mL} / \mathrm{h}$ every $15 \mathrm{~min}$ to a maximum of $180 \mathrm{~mL} / \mathrm{h}$, guided by the response. Normal births were taken care of by midwives, while doctors performed the operative deliveries. Throughout the study period, episiotomy was performed either mediolaterally or laterally. According to our routines and national guidelines, operative vaginal delivery was indicated if delivery had not taken place after $60 \mathrm{~min}$ of bearing down. We used vacuum extraction with a Malmström metal cup as the preferred procedure for operative vaginal delivery. Vacuum extraction was applied for mid-cavity and outlet release. A combination of low-dose ropivicaine/fentanyl was used for epidural analgaesia. Ethnicity was classified as Western, that is, originating from Europe or North America, or non-Western.

The intention of this study was to explore the effect of three obstetric practices (oxytocin augmentation $(\mathrm{O})$, episiotomy (E) and vacuum/forceps (VF)) and BW on obstetric anal sphincter injuries before other risk factors were considered. These main risk factors correlate as episiotomy is often used for instrumental deliveries and when large babies are expected. Furthermore, oxytocin augmentation is provided for failure to progress because of dystocia. Women with dystocia are more often delivered instrumentally than women without dystocia. This basic understanding of the birth dynamics of the first and second stages of labour indicates that the main risk factors may have a direct or indirect effect on obstetric anal sphincter injuries, and that the effects of categories across different explanatory variables are not constant on the outcome.

We analysed our dataset using the $\chi^{2}$ test and backward manual stepwise logistic regression analyses with $\mathrm{p}<0.05$ as significance level. We built and checked the fit of our regression model as proposed by Agresti. ${ }^{21}$ Step one compares the model including the highest order four-way interaction with a model without the four-way interaction. If the highest order product is not significant, Agresti proposes continuing by removing the highest order term with the highest non-significant $p$ value until all remaining terms have statistically significant $\mathrm{p}$ values. Four main predictors $(\mathrm{O}, \mathrm{E}, \mathrm{VF}$ and $\mathrm{BW})$ are used to predict the proportions of women with sphincter injuries. Confounders, possible risk factors in addition to the main factors of interest, were tested one by one and set to at least $10 \%$ change in any estimate in the model of best fit. Interaction terms were significant at $\mathrm{p}<0.05$. Statistical analyses were performed with IBM SPSS Statistics for Windows, V.19.0, IBM Corp, Armonk, New York, USA.

The Regional Committee for Medical and Health Research Ethics, Western Norway, approved the protocol as a quality assurance study in obstetric care, and fulfilling the requirements for data protection procedures (REK 2011-1247).

\section{RESULTS}

The study population comprised 15476 (27\%) of the 56517 women giving birth during the study period, including $1013(53 \%)$ of a total of 1894 women diagnosed with obstetric anal sphincter injuries.

The overall prevalence of obstetric anal sphincter injuries was $6.5 \%$. The rate declined from $9.6 \%$ in 1999 2000 to $2.8 \%$ in $2010-2012$. The characteristics of the study population and the prevalence of obstetric anal sphincter injuries are displayed in table 1.

The prevalence was higher in women who received oxytocin augmentation ( $8.0 \%$ vs $5.3 \%$ ), those who were delivered 
Table 1 Characteristics of the study population and the prevalence of obstetric anal sphincter injury

\begin{tabular}{|c|c|c|c|c|c|}
\hline \multirow[b]{2}{*}{ Factor } & \multicolumn{2}{|c|}{$\begin{array}{l}\text { Obstetric anal sphincter } \\
\text { injury }\end{array}$} & \multirow[b]{2}{*}{$\begin{array}{l}\text { In total } \\
N=15476\end{array}$} & \multirow[b]{2}{*}{$\begin{array}{l}\text { Prevalence } \\
\text { Per cent }\end{array}$} & \multirow[b]{2}{*}{ p Value } \\
\hline & $\begin{array}{l}\text { No } \\
N=14463 \\
\text { Per cent }\end{array}$ & $\begin{array}{l}\text { Yes } \\
\mathrm{N}=1013 \\
\text { Per cent }\end{array}$ & & & \\
\hline Time period & & & & & $<0.001$ \\
\hline 1999-2000 & 11.1 & 16.9 & 1781 & 9.6 & \\
\hline 2001-2003 & 19.8 & 30.7 & 3169 & 9.8 & \\
\hline 2004-2006 & 22.9 & 29.6 & 3611 & 8.3 & \\
\hline 2007-2009 & 25.5 & 14.3 & 3826 & 3.8 & \\
\hline 2010-2012 & 20.8 & 8.6 & 3089 & 2.8 & \\
\hline \multicolumn{6}{|l|}{ Maternal factors } \\
\hline Age (years) & & & & & $<0.001$ \\
\hline$<25$ & 26.6 & 19.3 & 4040 & 4.9 & \\
\hline $25-29$ & 33.5 & 37.6 & 5233 & 7.3 & \\
\hline $30-34$ & 17.8 & 20.8 & 2785 & 7.6 & \\
\hline$\geq 35$ & 22.1 & 22.2 & 3418 & 6.6 & \\
\hline Origin & & & & & $\mathrm{NS}^{*}$ \\
\hline Western & 90.5 & 92.0 & 14025 & 6.6 & \\
\hline Non-Western & 9.5 & 8.0 & 1451 & 5.6 & \\
\hline \multicolumn{6}{|l|}{ Obstetric factors } \\
\hline Epidural analgaesia & & & & & NS \\
\hline No & 58.1 & 57.7 & 8992 & 6.5 & \\
\hline Yes & 41.9 & 42.3 & 6484 & 6.6 & \\
\hline Oxytocin augmentation & & & & & $<0.001$ \\
\hline No & 55.6 & 44.7 & 8500 & 5.3 & \\
\hline Yes & 44.4 & 55.3 & 6976 & 8.0 & \\
\hline Active 2 nd stage of labour (min) & & & & & $<0.001$ \\
\hline Missing information & 0.6 & 0.3 & 92 & 3.3 & \\
\hline $0-14$ & 10.8 & 6.8 & 1627 & 4.2 & \\
\hline $15-29$ & 26.8 & 18.5 & 4063 & 4.6 & \\
\hline $30-59$ & 40.1 & 37.8 & 6181 & 6.2 & \\
\hline$\geq 60$ & 21.7 & 36.6 & 3513 & 10.6 & \\
\hline Episiotomy & & & & & NS \\
\hline No & 67.1 & 65.4 & 10372 & 6.4 & \\
\hline Yes & 32.9 & 34.6 & 5104 & 6.9 & \\
\hline Operative vaginal delivery & & & & & $<0.001$ \\
\hline No & 77.5 & 60.3 & 11817 & 5.2 & \\
\hline Yes & 22.5 & 39.7 & 3659 & 11.0 & \\
\hline \multicolumn{6}{|l|}{ Fetal factors } \\
\hline Birth weight (g) & & & & & $<0.001$ \\
\hline$<4000$ & 87.8 & 74.2 & 13454 & 5.6 & \\
\hline$\geq 4000$ & 12.2 & 25.8 & 2022 & 12.9 & \\
\hline Occiput posterior position & & & & & NS \\
\hline No & 95.4 & 94.8 & 14771 & 6.5 & \\
\hline Yes & 4.5 & 5.2 & 705 & 7.4 & \\
\hline
\end{tabular}

instrumentally $(11.0 \%$ vs $5.2 \%)$ and in those who gave birth to an infant weighing $\geq 4000 \mathrm{~g} \quad(12.9 \%$ vs $5.6 \%)$. Furthermore, the prevalence increased with longer durations of the active part of the second stage of labour.

After adopting the strategy of Agresti by deleting the highest statistically non-significant terms in the model until all remaining terms are statistically significant, we ended up with a best fitting model involving the threeway interaction of oxytocin augmentation, episiotomy and vacuum/forceps $(\mathrm{O} \times \mathrm{E} \times \mathrm{VF})$ and the two two-way interactions episiotomy/birth weight $(\mathrm{E} \times \mathrm{BW})$ and vacuum/forceps $(\mathrm{VF} \times \mathrm{BW})$ (model $\mathrm{A})$. We could resolve interaction terms into stratified analysis of eight strata of combinations of oxytocin augmentation, episiotomy and instrumental delivery for BW $<4000 \mathrm{~g}$, and four strata of combinations of episiotomy, instrumental delivery and BW $\geq 4000 \mathrm{~g}$, independent of oxytocin augmentation. The results are displayed in table 2 . 
Table 2 Model A: Stratified analyses of eight strata of combinations of oxytocin augmentation, episiotomy, instrumental delivery and birth weights $<4000 \mathrm{~g}$, and four strata of episiotomy, instrumental delivery and birth weights $\geq 4000 \mathrm{~g}$, independent of oxytocin augmentation

\begin{tabular}{|c|c|c|c|c|c|c|c|c|}
\hline Group & $\begin{array}{l}\text { Oxytocin } \\
\text { augmentation* }\end{array}$ & Episiotomy* & $\begin{array}{l}\text { Operative vaginal } \\
\text { delivery* }^{*}\end{array}$ & $\begin{array}{l}\text { Birth } \\
\text { weight } †\end{array}$ & $\begin{array}{l}\text { Women } \\
\mathbf{N}\end{array}$ & $\begin{array}{l}\text { OASI } \\
\text { N (\%) }\end{array}$ & OR & $95 \% \mathrm{Cl}$ \\
\hline 1 & - & - & - & - & 5328 & $198(3.7)$ & 1.0 & \\
\hline 2 & - & + & - & - & 1434 & 60 (4.2) & 1.1 & 0.8 to 1.5 \\
\hline 3 & - & + & + & - & 537 & $43(8.0)$ & 2.3 & 1.6 to 3.2 \\
\hline 4 & - & - & + & - & 316 & 47 (14.9) & 4.5 & 3.2 to 6.4 \\
\hline 5 & + & + & + & - & 1283 & $92(7.2)$ & 2.0 & 1.6 to 2.6 \\
\hline 6 & + & - & + & - & 896 & $103(11.5)$ & 3.4 & 2.6 to 4.3 \\
\hline 7 & + & - & - & - & 2621 & $148(5.6)$ & 1.6 & 1.3 to 1.9 \\
\hline 8 & + & + & - & - & 1039 & $61(5.9)$ & 1.6 & 1.2 to 2.2 \\
\hline 9 & $+/-$ & + & - & + & 418 & $40(9.6)$ & 2.7 & 1.9 to 3.9 \\
\hline 10 & $+1-$ & - & - & + & 977 & $104(10.6)$ & 3.1 & 2.4 to 4.0 \\
\hline 11 & $+/-$ & + & + & + & 393 & 55 (14.0) & 4.2 & 3.1 to 5.8 \\
\hline 12 & $+/-$ & - & + & + & 234 & $62(26.5)$ & 9.3 & 6.8 to 12.9 \\
\hline
\end{tabular}

\section{Crude OR and $95 \%$ Cls.}

*Used (+)/unused (-)

$\dagger \geq 4000 \mathrm{~g}(+) /<4000 \mathrm{~g}(-)$.

¥Obstetric anal sphincter injury.

From a clinical perspective we can simplify model A into model B by collapsing groups that comprise similar risks for sphincter injury by obstetric interventions despite overlapping CIs. Spontaneous delivery of an infant weighing $<4000 \mathrm{~g}$ without oxytocin augmentation and episiotomy was chosen as the reference group (group 1). We collapsed groups 1 and 2 as the OR for sphincter injury was similar with and without episiotomy in unstimulated, spontaneous births of normal-size infants. Groups 3 to 6 displayed the OR for sphincter injury in instrumental deliveries of normal-size infants with and without oxytocin augmentation and episiotomy. A marked difference in the OR for sphincter injury was observed between women delivered instrumentally with (groups 3 and 5) and without (groups 4 and 6) episiotomy, despite the fact that those stimulated with oxytocin had a non-significant lower OR for sphincter injury. It was, therefore, reasonable to collapse groups 3 and 5 and groups 4 and 6 . Furthermore, we collapsed groups 7 and 8 as the OR for sphincter injury was similar with and without episiotomy during spontaneous deliveries of infants $<4000 \mathrm{~g}$, regardless of oxytocin augmentation. Finally, the use of episiotomy appeared to be strongly associated with lower OR for sphincter injury in instrumental deliveries of infants $\geq 4000 \mathrm{~g}$ (groups 11 and 12 ). The modified model B (table 3 ) comprises a clinically relevant risk estimation of anal sphincter injury among the main modified risk factors for sphincter injury.

Age, origin of the mother and occiput posterior position had no confounding effect on ORs for obstetric anal sphincter injury across combinations of episiotomy, oxytocin augmentation, operative vaginal delivery and BW (groups A to $\mathrm{G}$ in table 3).

The unadjusted OR for the presence or absence of epidural analgaesia was 1.02; however, the adjusted OR for epidural analgaesia was 0.73 , (95\% CI 0.63 to 0.84 ), that is, epidural analgaesia was associated with a $30 \%$ lower OR of anal sphincter injury.

Table 3 Modified model displaying the collapsed non-significant strata (1-12) from table 2 into new strata (A-G)

\begin{tabular}{|c|c|c|c|c|c|c|c|c|}
\hline $\begin{array}{l}\text { Group } \\
\text { (group } \\
\text { in table 2) }\end{array}$ & $\begin{array}{l}\text { Oxytocin } \\
\text { augmentation* }\end{array}$ & Episiotomy* & $\begin{array}{l}\text { Operative } \\
\text { vaginal } \\
\text { delivery* }^{*}\end{array}$ & $\begin{array}{l}\text { Birth } \\
\text { weight† }\end{array}$ & $\begin{array}{l}\text { Women } \\
\mathbf{N}\end{array}$ & $\begin{array}{l}\text { OASI } \\
\text { N (\%) }\end{array}$ & OR & aOR (95\% CI) \\
\hline$A(1,2)$ & - & $+/-$ & - & - & 6762 & $258(3.8)$ & 1.0 & 1.0 \\
\hline $\mathrm{B}(7,8)$ & + & $+1-$ & - & - & 3660 & $209(5.7)$ & 1.5 & 1.8 (1.5 to 2.2$)$ \\
\hline$C(3,5)$ & $+/-$ & + & + & - & 1820 & $135(7.4)$ & 2.0 & 2.3 (1.8 to 2.8$)$ \\
\hline$D(4,6)$ & $+/-$ & - & + & - & 1212 & $150(12.4)$ & 3.6 & 4.1 (3.3 to 5.1$)$ \\
\hline$E(9-10)$ & $+/-$ & $+/-$ & - & + & 1395 & 144 (10.3) & 2.9 & 3.1 (2.5 to 3.9$)$ \\
\hline$F(11)$ & $+/-$ & + & + & + & 393 & 55 (14.0) & 4.1 & 4.7 (3.4 to 6.5$)$ \\
\hline G (12) & $+/-$ & - & + & + & 234 & $62(26.5)$ & 9.1 & 10.5 (7.6 to 14.4$)$ \\
\hline
\end{tabular}


The use of oxytocin augmentation increased with the duration of the second stage of labour over all the time periods from an average of $32 \%$ in the $<30$ min group, $46 \%$ in the 30-59 min group, and $65 \%$ (range $49-76 \%$ ) in the $\geq 60$ min group during the active second stage of labour. The prevalence of operative deliveries across all study periods was consistently between $45 \%$ and $49 \%$ when the active part of the second stage of labour lasted $\geq 60$ min versus $12-21 \%$ for durations of the second stage of labour of $<60 \mathrm{~min}$. We found strong associations between oxytocin augmentation and the duration of the second stage, and between operative delivery and the duration of the second stage (collinearity), which means that the duration of the second stage is measured through operative delivery and oxytocin augmentation.

\section{DISCUSSION}

We found that oxytocin augmentation during active labour was associated with a $80 \%$ increased OR of obstetric anal sphincter injury in women in TGCS group 1 giving spontaneous birth to an infant weighing $<4000 \mathrm{~g}$. We did not find an association between episiotomy and tears during spontaneous deliveries, but a significantly reduced association in all operative vaginal deliveries.

Oxytocin augmentation is widely used in delayed labour to prevent operative delivery. However, a Cochrane review concluded that a reduction of labour by $2 \mathrm{~h}$ was the only proven effect, and there was no effect on operative deliveries. ${ }^{18}$ Another recent review found the entire concept of active management of labour to be associated with a slightly reduced risk of caesarean delivery. ${ }^{22}$ As in other studies, we found that approximately $50 \%$ of nulliparous women received oxytocin augmentation. ${ }^{16}{ }^{17} 23$ There is reason to believe that guidelines for the diagnosis and treatment of protracted labour are unclear or inconsistently applied in daily practice. ${ }^{17}$ We hypothesise that stimulation with oxytocin may speed up the progress of the expulsive phase of labour leading to rushed situations, impaired communication with the mother, less focus on protection of the perineum and a controlled delivery of the head. Recent studies from Norway indicate that focus on these elements is important in preventing perineal injuries. ${ }^{24} 25$

Many authors have used logistic regression analysis to identify risk factors for obstetric anal sphincter injuries, but only a few have included oxytocin augmentation. Samuelsson et $a l^{14}$ Prager et $a l^{15}$ and Jander and Lyrenas $^{5}$ found oxytocin augmentation to be predictive of obstetric anal sphincter injuries in univariate analysis, but only Jander and Lyrenas confirmed this finding in multivariable analyses. Samuelsson $e t a l^{14}$ did not stratify by parity, which is a methodological weakness since the true effect of other factors is concealed by the strong impact of parity. Prager et $a l^{15}$ studied obstetric anal sphincter injuries in nulliparous women, entering oxytocin augmentation, duration of active second stage of labour and instrumental delivery into the same model.

Our study shows strong collinearity between a prolonged active second stage of labour and both oxytocin augmentation and instrumental delivery. We consider the duration of the active second stage of labour to be a 'proxy' for oxytocin augmentation and instrumental delivery, and not a risk factor for obstetric anal sphincter injury in itself. Long duration of the second stage is a time-related event before the expulsion of the head. During this latency the active forces do not inflict injury on the sphincter apparatus, the sphincter injury occurs during the expulsive phase. Consequently, we do not consider the duration of the active second stage as a risk factor for anal sphincter injuries.

Jander and Lyrenas ${ }^{5}$ conducted a single institution, retrospective, case-control study of 214 cases to explore 44 possible risk factors, and found that oxytocin augmentation was a significant risk factor for obstetric anal sphincter injuries in multivariable analyses (OR 2.00; $95 \%$ CI 1.13 to 3.53$)$. However, these researchers did not stratify by parity or state whether or not interactions were tested for. Furthermore, three older studies on the risk of obstetric anal sphincter injury included oxytocin use without differentiating whether oxytocin was provided for induction or augmentation purposes. ${ }^{26-28}$ Three large population-based studies on the risk of obstetric anal sphincter injuries did not include oxytocin augmentation in their analyses. ${ }^{178}$

The influence of epidural analgaesia on anal sphincter injuries is unclear. Eskandar and Shet $^{9}$ found a reduced risk, but did not stratify by parity. Dahl and Kjølhede $^{10}$ found epidural analgaesia to be an independent protective factor in nulliparous women. Poen et $a l^{29}$ stratified by parity and found a significantly increased OR associated with epidural analgaesia in nulliparous women. In our study, epidural analgaesia was associated with a significantly reduced OR for sphincter tears.

Our study takes into account four factors that exert their effect on the anal sphincter during the final minutes of delivery. As in previous studies, ${ }^{135}$ we found both operative vaginal delivery and high $\mathrm{BW}$ to be strongly associated with obstetric anal sphincter injuries. We found episiotomy to be associated with a lower prevalence of sphincter tears in operative vaginal deliveries, but not in spontaneous births. This is consistent with a large national registry study from Norway, ${ }^{1}$ but differs from other studies. ${ }^{8} 11133031$ In our study, neither oxytocin augmentation nor episiotomy were associated with obstetric anal sphincter injury during spontaneous delivery of an infant weighing $\geq 4000 \mathrm{~g}$.

Our methodological approach, stratifying by the factors that are active during the expulsive phase of labour and testing for confounders, is considered the strength of the study. This approach leads to a more detailed understanding of how oxytocin augmentation 
interacts with these major risk factors. Logistic regression analyses, without testing for possible interactions, would fail to reveal this information. This case-control study is based on prospectively collected data from a large unselected population, and represents all deliveries meeting the inclusion criteria that occurred during the study period, which make bias unlikely. Our department has a high proportion of vaginal deliveries. The overall caesarean delivery rate in our institution was $12.5 \%$ over the study period. For women in TGCS group 1 the acute caesarean section rate increased from $5.0 \%$ in 1999 to $7.5 \%$ in 2012 . Accordingly, the study population includes both high-risk and low-risk pregnancies, which adds to the external validity of our results.

However, some limitations apply. We cannot prove causality between oxytocin augmentation and obstetric anal sphincter injuries in an observational study. Furthermore, socioeconomic status, smoking, body mass index, maternal delivery positions, perineal support technique and the birth attendant's experience level may be possible risk modifiers not included in our database. Finally, single institution studies, also when based on unselected populations, should be interpreted with caution.

Our findings have some important implications. Birth attendants should be aware of the association between oxytocin augmentation and obstetric anal sphincter injuries in the large subgroup of nulliparous women giving spontaneous birth to a normal-size infant. More restrictive use of oxytocin may help prevent obstetric anal sphincter injuries. Implementation of evidencebased guidelines for using oxytocin augmentation should be encouraged. The WHO recommends the use of a partogram with an action line defining failure to progress. However, a recent Cochrane review could not confirm that such a partogram was beneficial in high resource settings. ${ }^{32}$ Given the doubtful benefits from augmentation of labour, randomised controlled trials are strongly needed, and we propose anal sphincter injury as one of the most important endpoints.

Moreover, our study supports restricted use of episiotomy during normal births and as a recommendation for operative vaginal deliveries. $\mathrm{BW}$ is an important, albeit unpredictable risk factor as weight estimation of a large fetus is unreliable. ${ }^{33}$

\section{Author affiliations \\ ${ }^{1}$ Department of Obstetrics and Gynecology, Stavanger University Hospital, Stavanger, Norway \\ ${ }^{2}$ Department of Clinical Medicine I, University of Bergen, Bergen, Norway \\ ${ }^{3}$ Women's Health and Perinatology Research Group, Department of Clinical Medicine, UiT The Arctic University of Norway, Tromsø, Norway \\ ${ }^{4}$ Department of GI Surgery, Stavanger University Hospital, Stavanger, Norway \\ ${ }^{5}$ National Center for Fetal Medicine, Trondheim University Hospital (St Olavs Hospital), Trondheim, Norway}

Acknowledgements The authors highly appreciate the work carried out by Leif K Gjessing, MD, in establishing the Obstetric Databases of Stavanger University Hospital.

Contributors ABR, FES, HK and TME have contributed to the idea and design of the research project. ABR and TME managed the data set and the statistical analyses were performed by FES. All authors have contributed to the interpretation of the results and the writing of the manuscript.

Funding This research received no specific grant from any funding agency in the public, commercial or not-for-profit sectors.

\section{Competing interests None.}

Ethics approval The Regional Committee for Medical and Health Research Ethics, Western Norway.

Provenance and peer review Not commissioned; externally peer reviewed.

Data sharing statement No additional data are available.

Open Access This is an Open Access article distributed in accordance with the Creative Commons Attribution Non Commercial (CC BY-NC 3.0) license, which permits others to distribute, remix, adapt, build upon this work noncommercially, and license their derivative works on different terms, provided the original work is properly cited and the use is non-commercial. See: http:// creativecommons.org/licenses/by-nc/3.0/

\section{REFERENCES}

1. Baghestan E, Irgens LM, Bordahl PE, et al. Trends in risk factors for obstetric anal sphincter injuries in Norway. Obstet Gynecol 2010;116:25-34.

2. Laine K, Skjeldestad FE, Sanda B, et al. Prevalence and risk factors for anal incontinence after obstetric anal sphincter rupture. Acta Obstet Gynecol Scand 2011;90:319-24.

3. Dudding TC, Vaizey CJ, Kamm MA. Obstetric anal sphincter injury: incidence, risk factors, and management. Ann Surg 2008;247:224-37.

4. Sultan AH, Thakar R, Fenner DE. Perineal and anal sphincter trauma: diagnosis and clinical management. New York; London: Springer, 2009.

5. Jander C, Lyrenas S. Third and fourth degree perineal tears. Predictor factors in a referral hospital. Acta Obstet Gynecol Scand 2001;80:229-34.

6. Hornemann A, Kamischke A, Luedders DW, et al. Advanced age is a risk factor for higher grade perineal lacerations during delivery in nulliparous women. Arch Gynecol Obstet 2010;281:59-64.

7. Handa VL, Danielsen BH, Gilbert WM. Obstetric anal sphincter lacerations. Obstet Gynecol 2001;98:225-30.

8. de Leeuw JW, Struijk PC, Vierhout ME, et al. Risk factors for third degree perineal ruptures during delivery. BJOG 2001;108:383-7.

9. Eskandar O, Shet D. Risk factors for 3rd and 4th degree perineal tear. J Obstet Gynaecol 2009;29:119-22.

10. Dahl C, Kjolhede P. Obstetric anal sphincter rupture in older primiparous women: a case-control study. Acta Obstet Gynecol Scand 2006;85:1252-8.

11. Raisanen S, Vehvilainen-Julkunen K, Gissler M, et al. Hospital-based lateral episiotomy and obstetric anal sphincter injury rates: a retrospective population-based register study. Am J Obstet Gynecol 2012;206:347 e1-6.

12. Murphy DJ, Macleod M, Bahl R, et al. A randomised controlled tria of routine versus restrictive use of episiotomy at operative vaginal delivery: a multicentre pilot study. BJOG 2008;115:1695-702 discussion 702-3.

13. Carroli G, Mignini L. Episiotomy for vaginal birth. Cochrane Database Syst Rev 2009;(1):CD000081.

14. Samuelsson E, Ladfors L, Wennerholm UB, et al. Anal sphincter tears: prospective study of obstetric risk factors. BJOG 2000;107:926-31.

15. Prager M, Andersson KL, Stephansson O, et al. The incidence of obstetric anal sphincter rupture in primiparous women: a comparison between two European delivery settings. Acta Obstet Gynecol Scand 2008;87:209-15.

16. Blix E, Pettersen $\mathrm{SH}$, Eriksen $\mathrm{H}$, et al. [Use of oxytocin augmentation after spontaneous onset of labor]. Tidsskr Nor Laegeforen 2002;122:1359-62.

17. Oscarsson ME, Amer-Wahlin I, Rydhstroem $\mathrm{H}$, et al. Outcome in obstetric care related to oxytocin use. A population-based study. Acta Obstet Gynecol Scand 2006;85:1094-8.

18. Bugg GJ, Siddiqui F, Thornton JG. Oxytocin versus no treatment or delayed treatment for slow progress in the first stage of spontaneous labour. Cochrane Database Syst Rev 2011;(7):CD007123.

19. Robson MS. Can we reduce the caesarean section rate? Best Pract Res Clin Obstet Gynaecol 2001;15:179-94. 
20. Norton C. Anal incontinence. In: Abrams P, Cardozo L, Khoury S, Wein A, eds. Incontinence. Plymouth: Health Publication Ltd, 2002:985-1044.

21. Agresti A. An introduction to categorical data analysis. 2nd edn. Hoboken, NJ; Chichester: Wiley-Interscience, 2007.

22. Brown HC, Paranjothy S, Dowswell T, et al. Package of care for active management in labour for reducing caesarean section rates in low-risk women. Cochrane Database Syst Rev 2013;9:CD004907.

23. Selin L, Almstrom E, Wallin G, et al. Use and abuse of oxytocin fo augmentation of labor. Acta Obstet Gynecol Scand 2009;88:1352-7.

24. Hals E, Oian P, Pirhonen T, et al. A multicenter interventional program to reduce the incidence of anal sphincter tears. Obstet Gynecol 2010;116:901-8.

25. Laine $\mathrm{K}$, Pirhonen $\mathrm{T}$, Rolland $\mathrm{R}$, et al. Decreasing the incidence of anal sphincter tears during delivery. Obstet Gynecol 2008;111:1053-7.

26. Moller Bek K, Laurberg S. Intervention during labor: risk factors associated with complete tear of the anal sphincter. Acta Obstet Gynecol Scand 1992;71:520-4.
27. Haadem K, Ohrlander S, Lingman G. Long-term ailments due to anal sphincter rupture caused by delivery-a hidden problem. Eur $J$ Obstet Gynecol Reprod Biol 1988;27:27-32.

28. Legino LJ, Woods MP, Rayburn WF, et al. Third- and fourth-degree perineal tears. 50 year's experience at a university hospital. J Reprod Med 1988;33:423-6.

29. Poen AC, Felt-Bersma RJ, Dekker GA, et al. Third degree obstetric perineal tears: risk factors and the preventive role of mediolateral episiotomy. Br J Obstet Gynaecol 1997;104:563-6.

30. Hartmann K, Viswanathan M, Palmieri R, et al. Outcomes of routine episiotomy: a systematic review. JAMA 2005;293:2141-8.

31. de Leeuw JW, de Wit C, Kuijken JP, et al. Mediolateral episiotomy reduces the risk for anal sphincter injury during operative vaginal delivery. BJOG 2008;115:104-8.

32. Lavender T, Hart A, Smyth RM. Effect of partogram use on outcomes for women in spontaneous labour at term. Cochrane Database Syst Rev 2013;7:CD005461.

33. Campbell S. Fetal macrosomia: a problem in need of a policy. Ultrasound Obstet Gynecol 2014;43:3-10. 